\title{
When Trichoscopy Reveals Things to us
}

\author{
Oukarfi S*, Ziani J, Douhi Z, Baybay H and Mernissi FH
}

Hospital University Hassan II, Morocco

*Corresponding author: Sara Oukarfi, Hospital university Hassan II, Route Sefrou, 30000 FèsVille-Nouvelle, Fès, Morocco, Tel: +212655311938; Email: oukarfisara@gmail.com

\section{Letter to Editor \\ Volume 5 Issue 1}

Received Date: January 10, 2020

Published Date: January 24, 2020

DOI: $10.23880 /$ cdoaj-16000202

\section{Dear Editor,}

A 40-year-old patient, with no notable pathological antecedents, followed in internal medicine for erythematous lupus with renal, immunological and cutaneous involvement retained on clinical, histological and immunological criteria using synthetic antimalarials, with oral corticotherapy.

Our opinion was sought for alopecic plaques in this patient who has been progressing for months with an increase in the number of plaques and itching for two months. Examination of the scalp showed several cicatricial and noncicatricial alopecia plates, weakly limited, erythematous background and positive pull sign (Figure 1). The rest of the clinical examination was unremarkable. Trichoscopy revealed (Figure 2): a background of erythema, large yelloworange dots with white perifollicular halos, [Figure 2: green circles] linear sinuous arborescent vessels [Figure 2: gray arrow]. Corkscrew hairs [Figure 2: red circle] and scales [Figure 2: blue arrow]. Apart from dermoscopic signs of lupus, there have been signs in favor of a tinea capitis, The mycological samples taken were in favor of a trichophyton rubrum, the patient was put on oral and topical griseofulvin as well as hygienic rules adapted with good clinical progress.

The scalp is frequent and inaugural in more than half of the cases of chronic lupus erythematosus and can remain isolated in $10 \%$ of the cases [1]. Tinea capitis, on the other hand, is a fungal infection that is the prerogative of children and remains rare in adults and mainly affects women.

The rarity of TC in adults is not well understood but can be explained by the fungistatic properties of post-pubertal sebum, the maturation of hair follicles and the immune system after adulthood which could protect against fungal invasion $[2,3]$. The clinical presentation is generally atypical in adults. Dermoscopy is a non-invasive tool that can help clinicians make the diagnosis. The most specific signs described were comma hair, corkscrew hair, zigzag hair and Morse code. for the signs in favor of lupus were the horny plugs, The aim of this presentation is to show the interest of trichoscopy for the diagnostic orientation of alopecia.

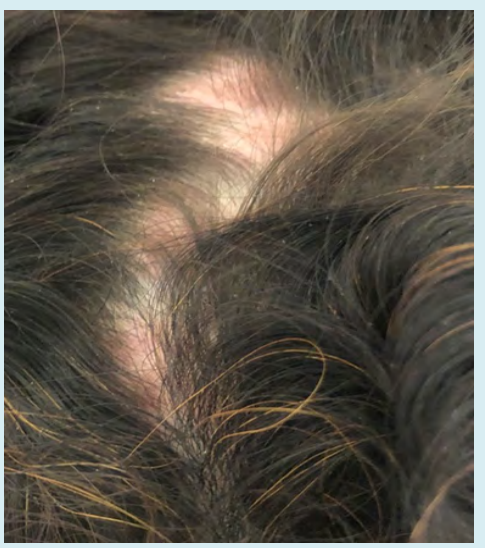

Figure 1: Clinical picture of cicatricial and non-cicatricial alopecia of the scalp.

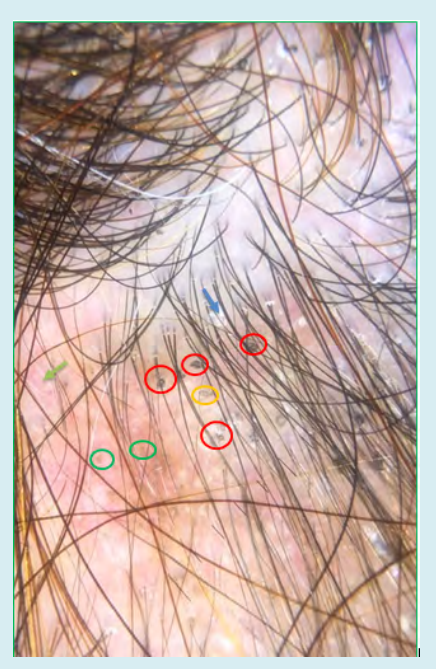

Figure 2: Trichoscopy associating signs in favor of tinea capitis and cutaneous lupus. 
Clinical Dermatology Open Access Journal

\section{References}

1. Francès C (2015) Manifestations cutanées des lupus érythémateux. EMC-Dermatologie 10: 1-14.

2. El-Khalawany M, Shaaban D, Hassan H, Abdalsalam F, Eassa B, et al. (2013) A multicenter clinicomycological study evaluating the spectrum of adult tinea capitis in Egypt. Acta Dermatovenerol Alp Pannonica Adriat 22(4):77-82.

3. Cervetti O, Albini P, Arese V, Ibba F, Novarino M, et al. (2014) Tinea capitis in adults. Adv Microbiol 4: 12.

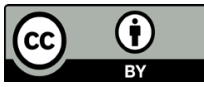

